\title{
Rancang Bangun Sistem Informasi Penjualan Obat Berbasis Website dengan Menggunakan Metode Waterfall
}

\author{
Ahmad Fauzi ${ }^{1}$, Dewi Wulandari ${ }^{2}$ \\ ${ }^{1}$ Prodi Sistem Informasi Akuntansi, Universitas Bina Sarana Informatika \\ 2Sistem Informasi, STMIK Nusa Mandiri \\ 1'Ahmad.fzx@bsi.ac.id, 2Dewiiwulandari106@gmail.com
}

\begin{abstract}
In this era of globalization, information technology is speeding up. In managing the information required good technology because the information has a great value for a company. And computer technology today with its increasingly sophisticated processing speed has enabled the development of computer-based information systems. Problems that exist in Kauman Apothecary is about the data processing that is still done manually, ranging from the admission process of incoming drugs, drugs out, often the absence of matching stock between the data with the original drug, as well as in making reports that still use microsoft excel. The design of the system is described by UML modeling, drug sales information system on web-based pharmacy kauman intranet this is the best solution, can improve the quality of data processing drugs in pharmacies kauman. And with the creation of this information system, can help simplify data processing more leverage, while keeping data safe and minimize the data kerangkapan. The design of webbased drug sales information system is made using PHP and MySQL.
\end{abstract}

Keywords: Information System, Sales, Kauman Pharmacy

\begin{abstract}
Abstrak: Dalam era globalisasi sekarang ini, teknologi informasi melaju dengan cepatnya. Dalam mengelola informasi dibutuhkan teknologi yang baik karena informasi mempunyai nilai yang besar bagi suatu perusahaan. Dan teknologi komputer sekarang ini dengan kecepatan prosesnya yang semakin canggih telah memungkinkan pengembangan sistem informasi berbasis komputer. Masalah yang ada pada Apotek Kauman yaitu mengenai pengolahan datadatanya yang masih dilakukan secara manual, mulai dari proses penerimaan obat masuk, obat keluar, sering tidak adanya kecocokan stok antara data dengan obat aslinya, serta dalam membuat laporan yang masih menggunakan microsoft excel. Perancangan sistem digambarkan dengan pemodelan UML, sistem informasi penjualan obat pada apotek kauman berbasis web intranet ini merupakan solusi yang terbaik, dapat meningkatkan kualitas pengolahan data obat di apotek kauman. Dan dengan dibuatnya sistem informasi ini, dapat membantu mempermudah pengolahan data lebih maksimal, sekaligus menjaga data tetap aman dan meminimalisir adanya kerangkapan data. Perancangan sistem informasi penjualan obat berbasis web ini dibuat menggunakan PHP dan MySQL
\end{abstract}

Kata Kunci: Sistem Informasi, Penjualan, Apotek Kauman.

This is an open access article distributed under the Creative Commons Attribution License, which permits unrestricted use, distribution, and reproduction in any medium, provided the original work is properly cited. (C2019 by author and IJSE-Indonesian Journal on Software Engineering.

\section{A. PENDAHULUAN}

Apotek merupakan salah satu jenis usaha dibidang perobatan yang sangat memerlukan adanya sistem informasi pengolahan data untuk mempermudah dan memperlancar kinerjanya. Sekarang ini, masih banyak penulisan dan pencatatan data-data obat pada apotek yang dilakukan secara konvensional. Cukup banyak apotek yang masih memperdayakan tenaga manusia untuk mengolah data-data yang ada demi memperlancar usahanya(Utami Tri, 2015).

Salah satunya adalah Apotek Kauman permasalahan yang terjadi yaitu sering tidak adanya kecocokan antara data dengan obat aslinya, dan ini akan mengakibatkan tidak efektifnya data 
stok opname obat yang dihasilkan.

Tidak tepat waktu dibuatnya laporan pembelian obat ke supplier dan penjualan obat ke konsumen perbulan, karena setiap transaksi yang terjadi tidak direkap dengan waktu yang pasti, misalkan perminggu atau perbulan. Sehingga laporan yang dihasilkan atau dibuat tidak efektif dan efesien.

Menurut (Astuti, 2013)) berpendapat bahwa: Apotek Jati Farma mempunyai permasalahan mengenai pengolahan data yang masih bersifat konvensional, yaitu aktivitas pada apotek masih dilakukan pencatatan, baik itu transaksi penjualan ataupun pembelian barang ke dalam sebuah buku, sehingga membuat kinerja apotek menjadi kurang efektif dan efesien. Karena itu dibutuhkan sebuah sistem yang dapat mengatasi hal tersebut.

Dan tujuan dari penelitian ini adalah untuk membuat sistem pencatatan obat (pembelianpenjualan) yang bersifat komputerisasi. Manfaatnya adalah agar memudahkan proses pencatatan data obat, baik itu pembelian ataupun penjualan.

Dari pembuatan sistem ini, harapannya bias meringankan tugas asisten apoteker dan membuat kinerja apotek menjadi lebih efektif dan efesien.

Oleh sebab itu, dibutuhkan sebuah sistem yang dapat mendata daftar-daftar data obat tersebut dengan melakukan perbaikan dalam pengolahan data. Perbaikan yang dilakukan yaitu membuat sistem pencatatan dengan menggunakan sistem aplikasi penjualan berbasis web, baik dari segi pendataan barang persediaan, pencatatan data transaksi, dan proses yang lainnya yang berhubungan dengan aktivitas pada apotek yang bersangkutan.

\section{B. TINJAUAN PUSTAKA}

\section{Sistem}

Menurut Sutopo (2012:85) "Sistem kumpulan elemen yang saling berhubungan dan saling bekerjasama untuk mencapai tujuan tertentu". Sistem diklasifikasikan menjadi dua kategori, yaitu sistem fisik (pshysical system) dan sistem konseptual (conseptual system). Secara umum kedua sistem meliliki elemen yang sama yaitu input dan output, serta transformasi(Maulidah, N., Pebrianto, R., Supriyadi, R., \& Fauzi, 2019). Sistem fisik merupakan sistem seperti gedung, uang manusia dan lainnya. Sedangkan sistem konseptual adalah sistem di mana input dan output berupa data dan informasi. Suatu sistem yang tidak memiliki feedback disebut openloop-system yaitu sistem yang dapat berhubungan dengan lingkungan luar seperti sistem pintu, dimana yang memiliki feedback disebut close-loop-system yaitu sistem yang tidak dipengaruhi oleh lingkungan.

Sistem adalah suatu jaringan kerja dari prosedur-prosedur yang saling berhubungan, terkumpul bersama-sama untuk melakukan suatu kegiatan atau untuk tujuan tertentu (Utami Tri, 2015)

\section{Informasi}

Informasi adalah data yang telah diproses sedemikian rupa sehingga meningkatkan pengetahuan seseorang yang menggunakan (Kusuma, 2012). Informasi adalah data yang telah diklasifikasikan atau diolah atau diinterpretasikan untuk digunakan dalam proses pengambilan keputusan (Sutabri, n.d.)

Menurut McLeod dalam (Sutopo, 2012)(Madcoms, 2011) Informasi adalah data yang diolah sehingga dapat dijadikan dasar untuk pengambilan keputusan yang tepat. Informasi merupakan komoditas yang sangat penting bagi perusaahaan, karena dengan adanya informasi akan membantu dalam operasi dan pengambilan keputusan sehari-hari. Untuk memberikan gambaran yang jelas tentang istilah data dan informasi dalam hubungannya deengan proses penyediaan informasi. Dengan adanya sistem yang baik diharapkan dapat menghasilkan suatu informasi yang berkualitas tinggi. Informasi yang baik tersebut mempunyai kreteria sebagai berikut :

a. Relevan yaitu informasi yang relevan berkaitan sejauh mana informasi tersebut dapat membuat perbadaan untuk alternatif pengambilan keputusan.

b. Akurat yaitu keakuratan informasi berkaitan dengan ketetapan dan keandalan informasi tersebut sehingga informasi yang akurat, berarti bebas dari kesalahan dan tidak menyesatkan bagi pemakai informasi. 
c. Tepat waktu yaitu ketepatan waktu sebuah informasi sangat penting, karena informasi tersebut harus tersedia pada saat dibutuhkan karena berhubungan dengan pengambilan keputusan atau kebijakan.

d. Ringkas yaitu keringkasan sebuah informasi berarti informasi tersebut sudah digolongkan dan disajikan dalam bentuk yang tidak terlalu detail sehingga tidak membingungkan para pemakai informasi.

e. Jelas yaitu informasi yang jelas menunjukan tingkat kemampuan informasi tersebut sudah digolongkan dan disajikan dalam bentuk yang tidak terlalu rinci.

f. Dapat diukur yaitu berhubungan dengan konsep pengukuran informasi yang dapat diukur akan menambah nilai informasi tersebut.

g. Konsisten yaitu sebuah informasi berhubungan dengan kemampuan untuk dapat dibandingkan dengan informasi sejenis dari fungsi yang berbeda atau informasi yang sejenis dengan waktu yang berbeda.

Informasi adalah data yang telah diproses sedemikian rupa sehingga meningkatkan pengetahuan seseorang yang menggunakan[8].

Informasi adalah data yang telah diklasifikasikan atau diolah atau diinterpretasikan untuk digunakan dalam proses pengambilan keputusan

\section{Sistem Informasi}

Menurut (Sibero, 2013), memberikan batasan bahwa "Sistem informasi adalah hasil pengolahan dari informasi yang saling terkait antara yang satu dengan yang lainnya". Sistem Informasi adalah suatu sistem didalam suatu organisasi yang mempertemukan kebutuhan pengolahan transaksi harian yang mendukung fungsi operasi organisasi yang bersifat manajerial dengan kegiatan strategi dari suatu organisasi untuk dapat menyediakan laporanlaporan yang diperlukan oleh pihak luar tertentu(Sutabri, n.d.)

\section{Konsep Dasar Model Pengembangan Sistem}

Menurut (Rosa, 2011) "Model SDLC air terjun (waterfall) sering juga disebut model sekunsial linier (sequential linear) atau alur hidup klasikal (classic life cycle)". Model air terjun menyediakan pendekatan alur hidup perangkat lunak secara sekuensial atau terurut dimulai dari analisis, desain, pengkodean, pengujian dan tahap pendukung / support.

Metode ini memberikan pendekatan-pendekatan sistematis dan berurutan bagi pengembangan sistem informasi. Berikut adalah gambar pengembangan sistem perangkat lunak dengan metode waterfall.

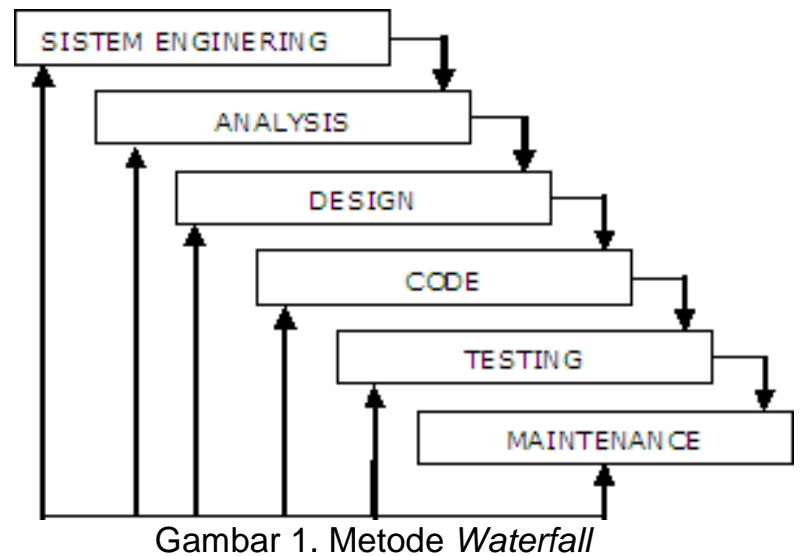

Sumber : (Rosa, 2011)

\section{Konsep Dasar Pemprograman}

Pemrograman terstruktur adalah konsep atau paradigma atau sudut pandang pemrograman yang membagi-bagi program berdasarkan fungsi-fungsi atau prosedur-prosedur yang dibutuhkan program komputer. Menurut (Rosa, 2011). 
Fungsi-fungsi dan prosedur-prosedur ditulis secara sekuensial atau terurut dari atas kebawah sesuai dengan kebergantungan antara fungsi atau prosedur. Pemodelan pada pemrograman terstruktur lebih fokus bagaimana memodelkan data dan fungsi-fungsi atau prosedur-prosedur yang harus dibuat. Jenis paradigma pemrograman yang digunakan dapat dideteksi dari bahasa pemrograman apa yang akan digunakan untuk membuat program, baru setelah itu ditentukan paradigma pemrograman apa yang akan digunakan.

\section{Konsep Dasar Sistem Informasi Penjualan Apotek}

Menurut Astuti, (Astuti, 2013) Sistem Informasi Penjualan Apotek adalah suatu kumpulan informasi yang mendukung suatu proses pemenuhan kebutuhan suatu informasi yang bertanggung jawab untuk menyediakan informasi penjualan obat dalam satu kesatuan proses yang bertujuan untuk meningkatkan pelayanan apotek.

\section{METODE PENELITIAN}

Pada penelitian ini metode dimulai dengan pengumpulan data. Pengumpulan data dilakukan dengan beberapa metode diantaranya observasi,wawancara dan stuidi pustaka.

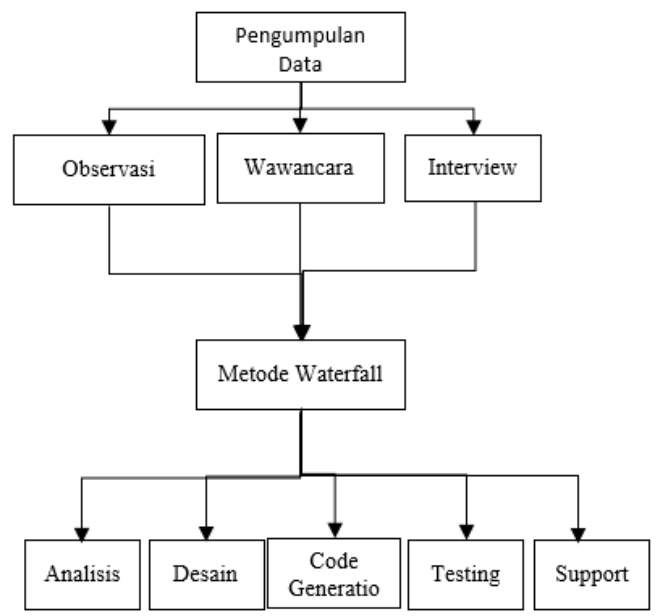

Gambar 2. Metode Penelitian

Dalam penyusunan penelitian ini,agar hasil yang diinginkan baik dan tepat,penulis melakukan beberapa metode dalam pengumpulan data referensinya diantaranya:

\section{Observasi}

Melalui metode ini penulis melakukan tinjauan langsung pada Apotek Kauman untuk mendapatkan informasi tentang profile perusahaan dan datadata yang diperlukan dalam pembuatan skripsi ini(Fathansyah., 2007).

2. Wawancara

Wawancara adalah pendekatan secara langsung dengan sumber data dan terjadi proses komunikasi untuk mendapatkan datanya. Penulis melakukan tanya jawab langsung kepada pemilik Apotek Kauman yaitu Riski Amalia, S.Far., Apt tentang permasalahan yang dihadapi dalam proses penjualan. Sehingga penulis dapat memperoleh data yang lebih akurat dalam pemecahan masalah yang terjadi pada apotek tersebut.

3. Studi Pustaka

Metode studi pustaka ini penulis, mendapat sumber data dari buku-buku dan makalahmakalah yang berhubungan dengan studi literature pada buku atau referensi yang berkaitan dengan sistem informasi, perancangan desain web, artikel-artikel dan lain sebagainya serta situs-situs internet yang menunjang(Mujiati, 2015).

Model pengembangan sistem yang digunakan pada penelitian inj adalah model waterfall. Model SDLC ini sering juga disebut model sekuensial linier atau alur hidup klasik. Model 
waterfall menyediakan pendekatan alur hidup perangkat lunak secara sekuensial atau terurut dimulai dari analisis kebutuhan software, desain, pengodean, pengujian, dan tahap pendukung (support)(Hidayat et al., 2017).

\section{HASIL DAN PEMBAHASAN}

Penggunaan sistem informasi pada sebuah bidang usaha bertujuan untuk membantu menambah kelancaran dalam proses pengolahan data. Selain itu sistem informasi yang terkomputerisasi juga dapat mengurangi permasalahan yang berkaitan dengan hilang atau rusaknya data dan meminimalisir sebuah kesalahan dalam pengolahan datanya.

Desain dilakukan dengan menggunakan diagram activity diagram, use case diagram, ERD, LRS, Component Diagram, dan Deployment Diagram.

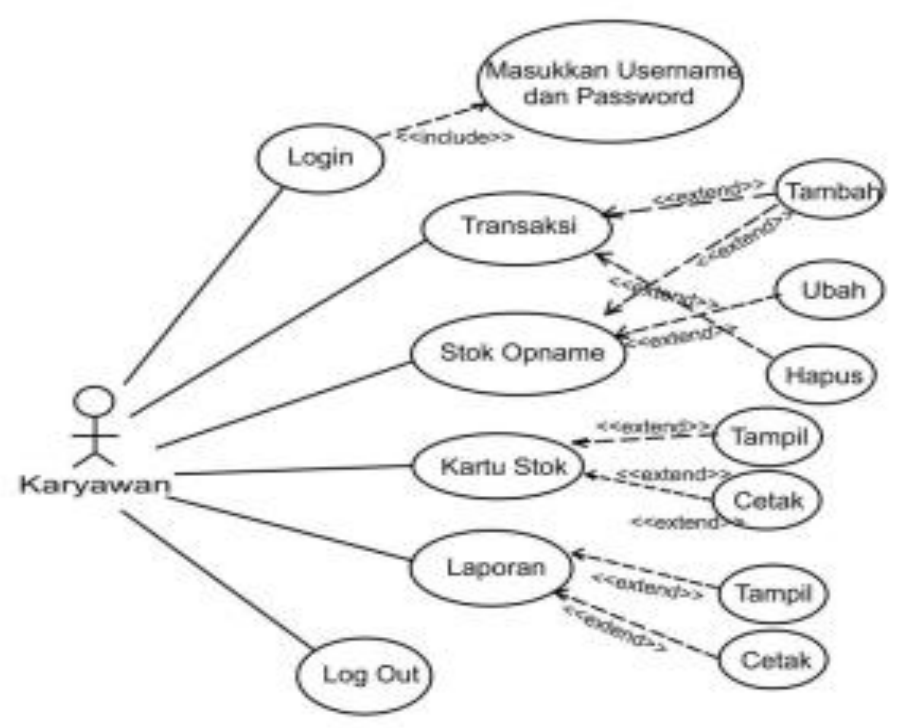

Gambar 3.cUse Case Diagram

Gambar 3 menunjukan keseluruhan aktivitas yang dilakukan karyawan pada sistem informasi apotek kauman.

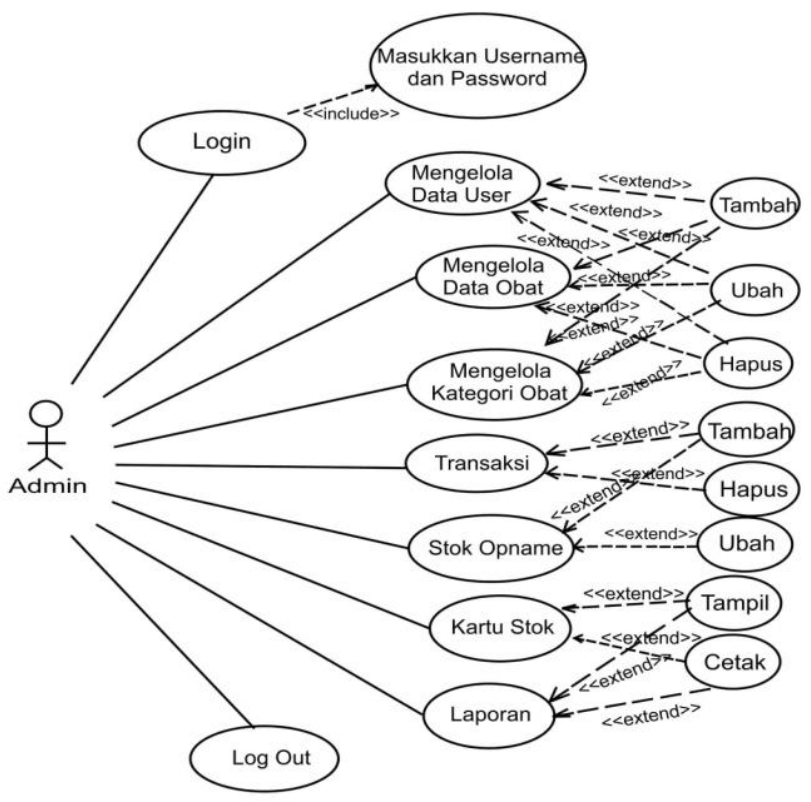

Gambar 4.Use Case Diagram Halaman Admin 
Gambar 4 menunjukan keseluruhan aktivitas yang dilakukan admin pada sistem informasi apotek kauman.

\section{Activity Diagram}

Activity Diagram merupakan diagram flowchart yang diperluas yang menunjukkan aliran kendali satu aktifitas ke aktifitas lain.. Berikut Activity Diagram sistem penjualan obat berbasis web intranet yang diusulkan.

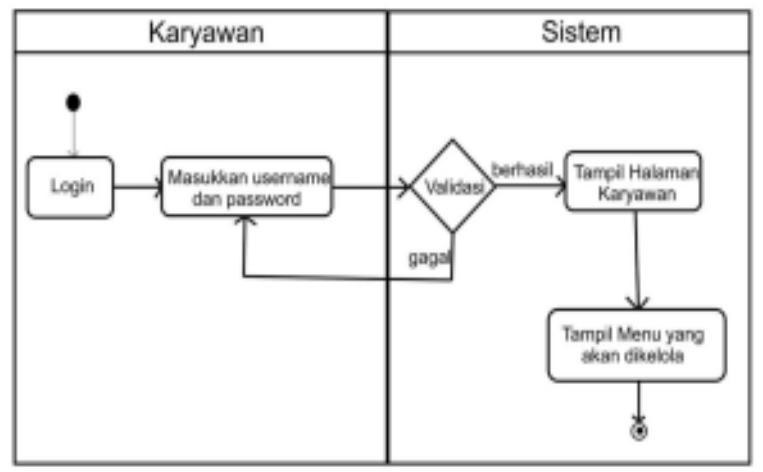

Gambar 5. Activity Diagram Halaman Login Karyawan

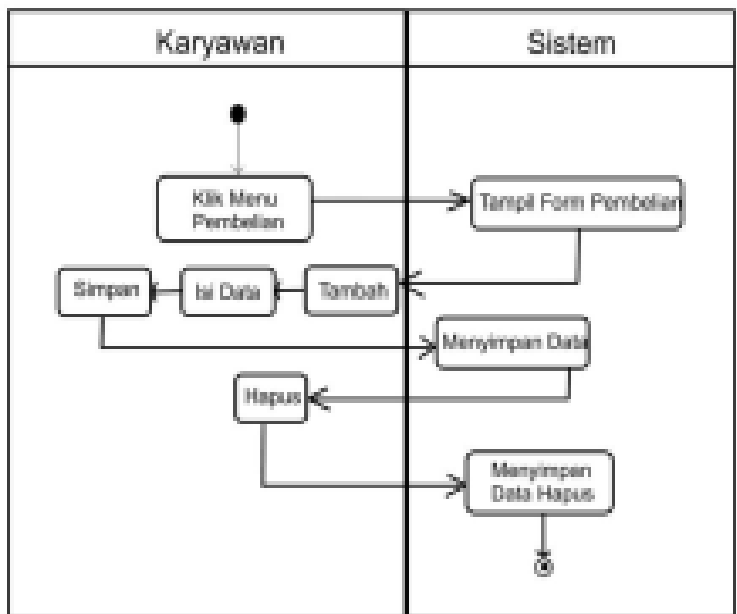

Gambar 6.Activity Diagram Karyawan Mengelola Transaksi Pembelian Obat

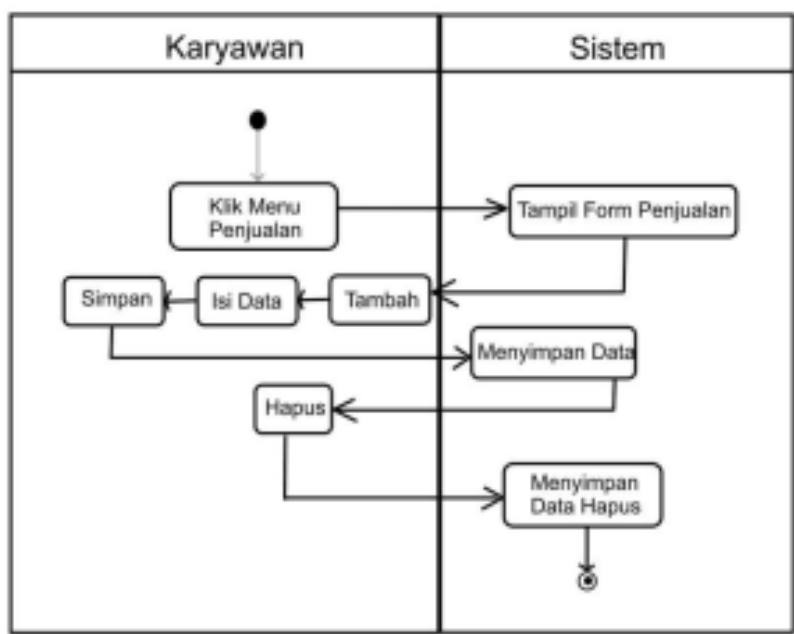

Gambar 7.Activity Diagram Karyawan Mengelola Transaksi Penjualan Obat 


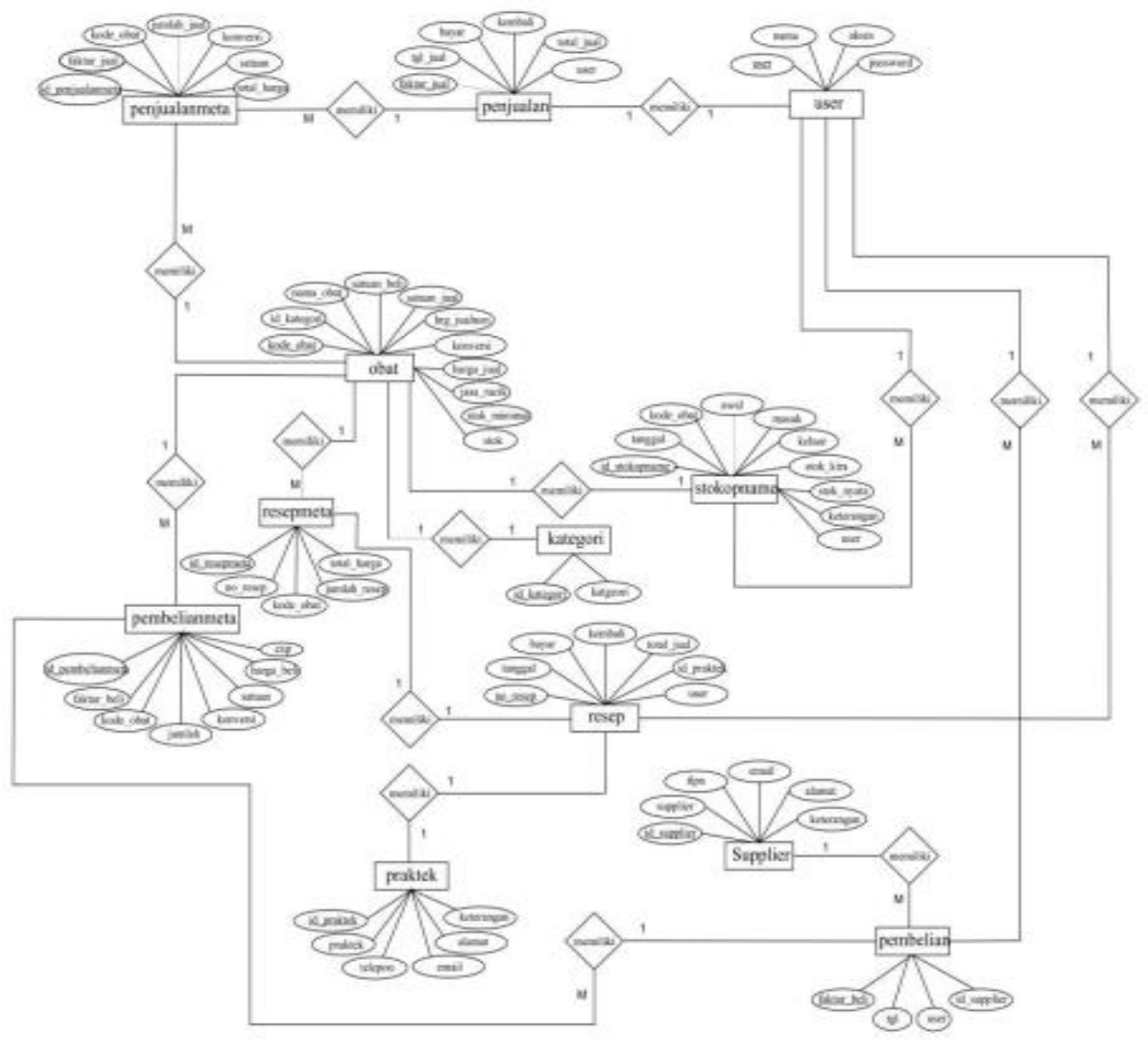

Gambar 8.Entity Relationship Diagram

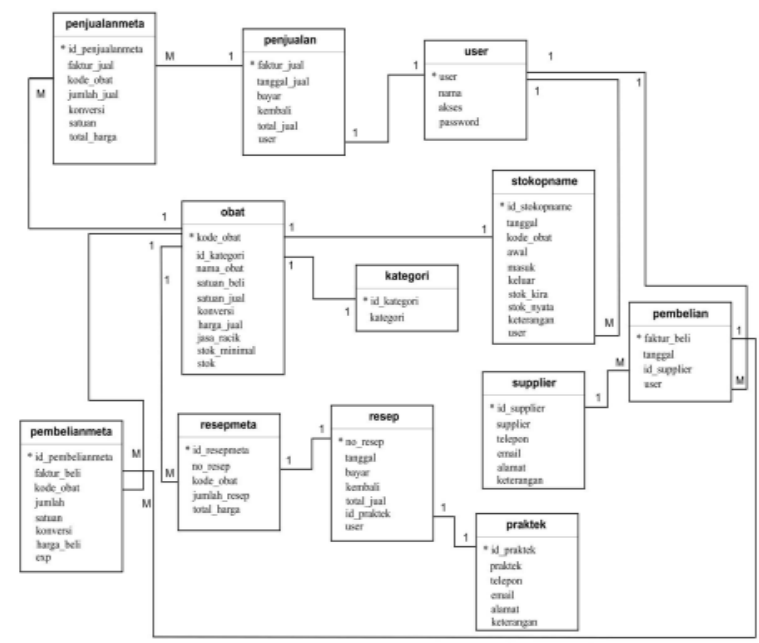

Gambar 9.Logical Record Structure

Component diagram menggambarkan struktur dan hubungan antar komponen piranti lunak, termasuk ketergantungan (dependency) di antaranya,komponen piranti lunak adalah modul berisi code, baik berisi source code maupun binary code, baik library maupun executable, baik yang muncul pada compile time, link time, maupun run time. Komponen dapat juga berupa interface, yaitu kumpulan layanan yang disediakan sebuah komponen untuk komponen lain.berikut gambar diagramnya. 


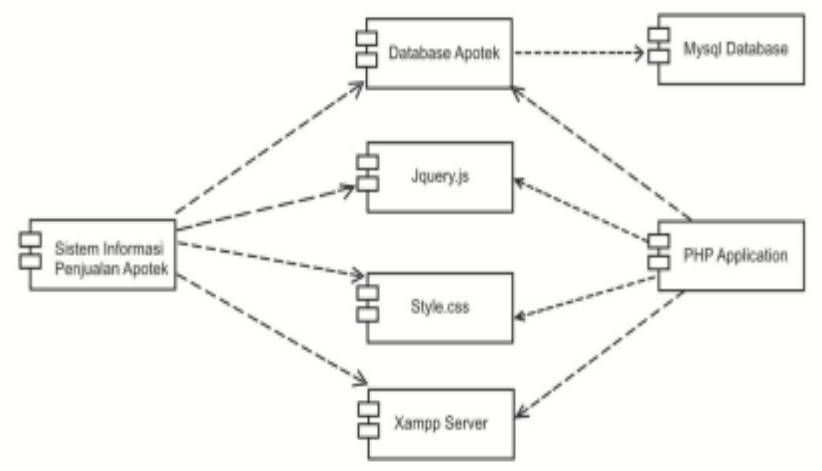

Gambar 10.Component Diagram Sistem Informasi Penjualan Obat

Diagram deployment mewakili pandangan pengembangan sistem sehingga hanya akan ada satu diagram deployment untuk satu sistem. Diagram deployment terdiri dari node dan node merupakan perangkat keras fisik yang digunakan untuk menyebarkan aplikasi. Tiap node pada diagram deployment mewakili satu unit komputasi sistem yang dalam banyak hal merupakan bagian dari perangkat keras, berikut gambar diagramnya.

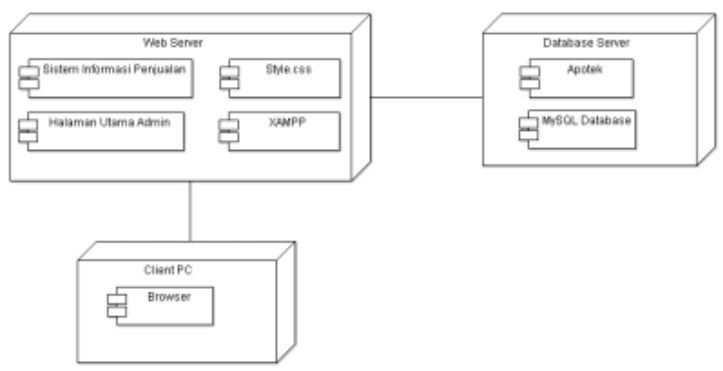

Implementasi

Gambar 11. Deployment Diagram Sistem Penjualan Obat

Setelah perancangan sistem selesai, kemudian dilakukan implementasi. Hasil impementasi terlihat pada rancangan antara muka yang dapat digunakan untuk memenuhi kebutuhan sistem.

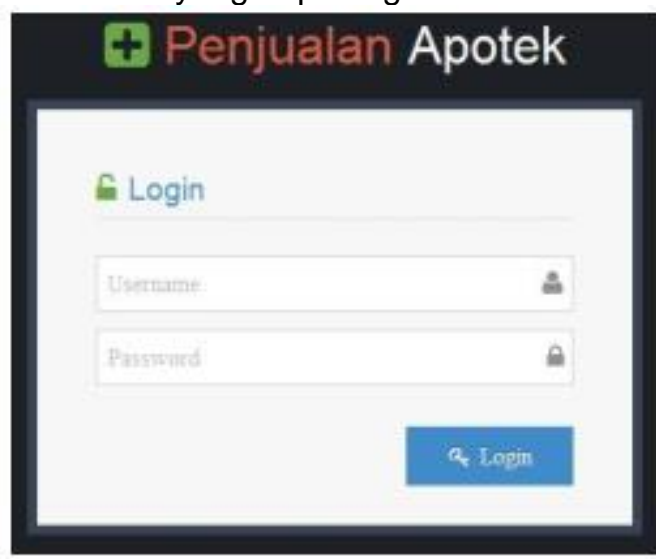

Gambar 12.Halaman Login Admin dan Karyawan 


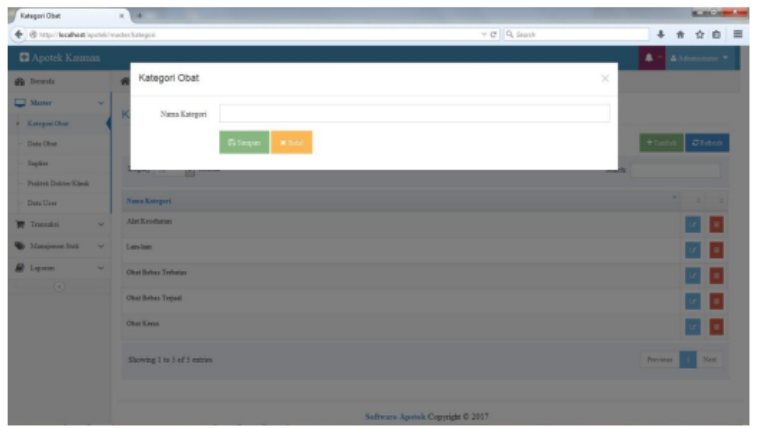

Gambar 13.Tampilan Halaman Admin Menu Master Tambah Kategori

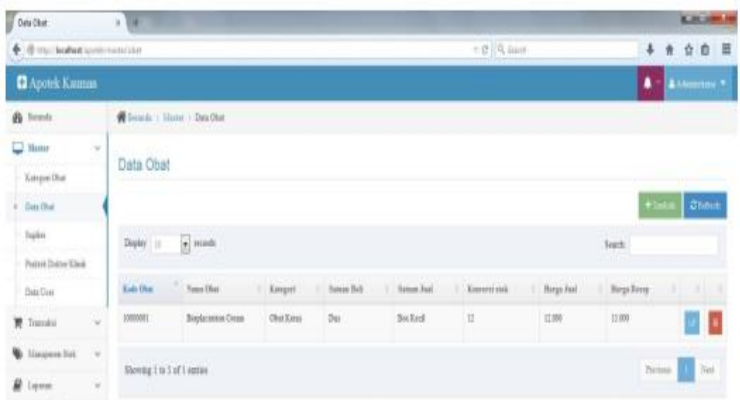

Gambar 14.Tampilan Halaman Admin Menu Master Data Obat

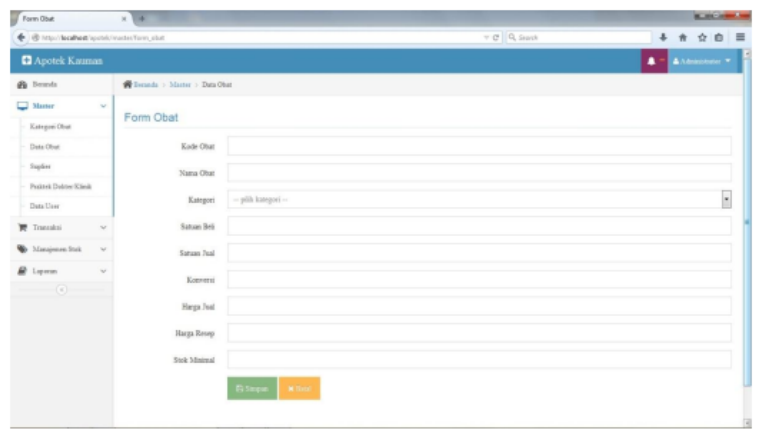

Gambar 15.Tampilan Halaman Admin Form Tambah Data Obat

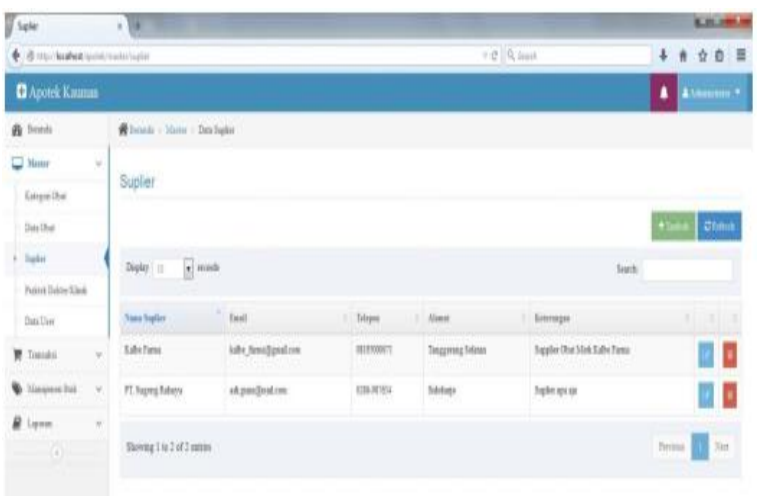

Gambar 16.Tampilan Halaman Admin Menu Master Supplier 


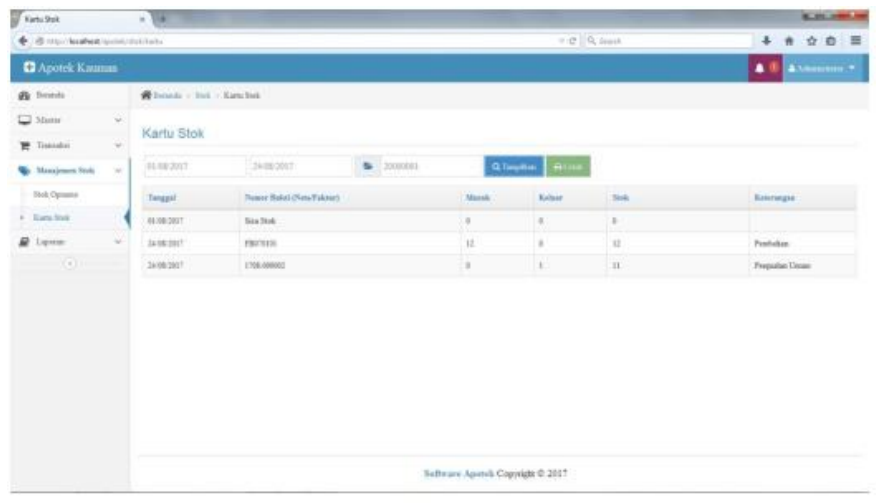

Gambar 17.Tampilan Halaman Admin Menu Kartu Stok

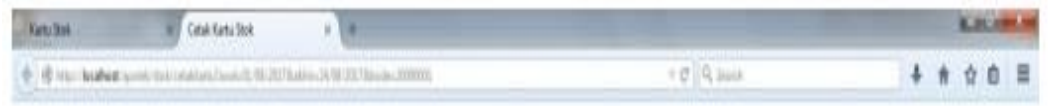

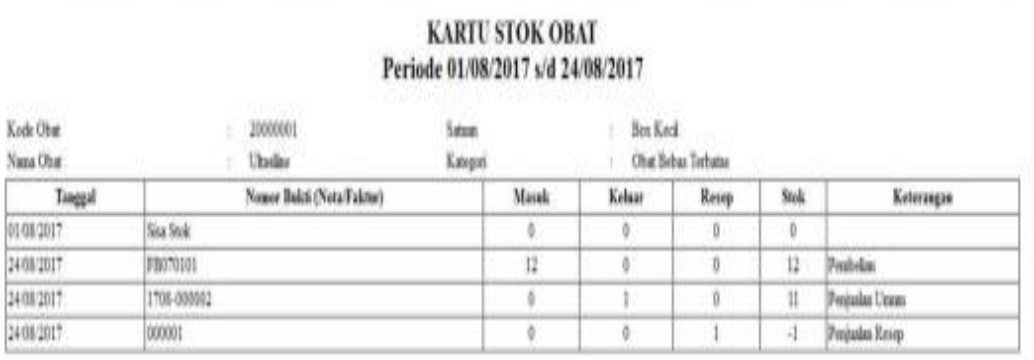

Gambar 18. Halaman Tampilan Cetak Kartu Stok

Setelah diimplementasikan, kemudian perlu diketahui kinerja dari sistem informasi yang telah dibangun. Untuk mengetahuinya, maka dilakukan testing. Metode black box testing dilakukan untuk mengevaluasi program.

Tabel 3.Hasil Black Box Testing Form Login Admin

\begin{tabular}{|c|c|c|c|c|c|}
\hline No & $\begin{array}{c}\text { Skenario } \\
\text { Pengujian }\end{array}$ & Test Case & $\begin{array}{l}\text { Hasil yang } \\
\text { diharapkan }\end{array}$ & $\begin{array}{c}\text { Hasil } \\
\text { Pengujian }\end{array}$ & Kesimpulan \\
\hline 1 & $\begin{array}{l}\text { Mengosongkan } \\
\text { semua isian data } \\
\text { form Login. }\end{array}$ & $\begin{array}{c}\text { Username } \\
\text { (kosong) } \\
\text { Password } \\
\text { (kosong) }\end{array}$ & $\begin{array}{l}\text { Sistem akan } \\
\text { menolak akses }\end{array}$ & $\begin{array}{l}\text { Sesuai } \\
\text { harapan }\end{array}$ & Valid \\
\hline 2 & $\begin{array}{l}\text { Hanya } \\
\text { memasukan data } \\
\text { Username dan } \\
\text { mengosongkan } \\
\text { data password. }\end{array}$ & $\begin{array}{l}\text { Username } \\
\text { (admin) } \\
\text { Password } \\
\text { (kosong) }\end{array}$ & $\begin{array}{l}\text { Sistem akan } \\
\text { menolak akses } \\
\text { login dan akan } \\
\text { menampilkan } \\
\text { pesan } \\
\text { "Username dan } \\
\text { password masih } \\
\text { salah" }\end{array}$ & $\begin{array}{l}\text { Sesuai } \\
\text { harapan }\end{array}$ & Valid \\
\hline 3 & $\begin{array}{l}\text { Hanya } \\
\text { memasukan data } \\
\text { password dan }\end{array}$ & $\begin{array}{l}\text { Username } \\
\text { (kosong) }\end{array}$ & $\begin{array}{l}\text { Sistem akan } \\
\text { menolak akses } \\
\text { login }\end{array}$ & $\begin{array}{c}\text { Sesuai } \\
\text { harapan }\end{array}$ & Valid \\
\hline
\end{tabular}




\begin{tabular}{|c|c|c|c|c|c|}
\hline & $\begin{array}{l}\text { mengosongkan } \\
\text { data username. }\end{array}$ & $\begin{array}{c}\text { Password } \\
\text { (admin) }\end{array}$ & & & \\
\hline 4 & $\begin{array}{l}\text { Menginputkan } \\
\text { dengan } \\
\text { kondisi salah } \\
\text { satu data } \\
\text { benar dan satu } \\
\text { lagi salah, lalu } \\
\text { langsung } \\
\text { mengklik } \\
\text { tombol } \\
\text { "login". }\end{array}$ & $\begin{array}{l}\text { Username } \\
\text { : } 001 \\
\text { (salah) } \\
\text { Password } \\
\text { : admin } \\
\text { (benar) }\end{array}$ & $\begin{array}{l}\text { Sistem akan } \\
\text { menolak akses } \\
\text { login dan akan } \\
\text { menampilkan } \\
\text { pesan } \\
\text { "Username dan } \\
\text { password masih } \\
\text { salah" }\end{array}$ & $\begin{array}{c}\text { Sesuai } \\
\text { Harapan }\end{array}$ & Valid \\
\hline 5 & $\begin{array}{l}\text { Menginputkan } \\
\text { dengan } \\
\text { kondisi salah } \\
\text { satu data } \\
\text { benar dan satu } \\
\text { lagi salah, lalu } \\
\text { langsung } \\
\text { mengklik } \\
\text { tombol } \\
\text { "login". }\end{array}$ & $\begin{array}{l}\text { Username } \\
\text { : admin } \\
\text { (benar) } \\
\\
\text { Password } \\
\text { : } 12345 \\
\text { (salah) }\end{array}$ & $\begin{array}{l}\text { Sistem akan } \\
\text { menolak akses } \\
\text { login dan akan } \\
\text { menampilkan } \\
\text { pesan } \\
\text { "Username dan } \\
\text { password masih } \\
\text { salah" }\end{array}$ & $\begin{array}{c}\text { Sesuai } \\
\text { Harapan }\end{array}$ & Valid \\
\hline 6 & $\begin{array}{l}\text { Menginputkan } \\
\text { data login } \\
\text { yang benar, } \\
\text { lalu mengklik } \\
\text { tombol } \\
\text { "login". }\end{array}$ & $\begin{array}{l}\text { Username } \\
\text { : admin } \\
\text { (benar) } \\
\text { Password } \\
\text { : admin } \\
\text { (benar) }\end{array}$ & $\begin{array}{l}\text { Sistem } \\
\text { menerima } \\
\text { akses login } \\
\text { kemudian } \\
\text { langsung } \\
\text { menampilkan } \\
\text { halaman } \\
\text { utama } \\
\text { Karyawan }\end{array}$ & $\begin{array}{c}\text { Sesuai } \\
\text { Harapan }\end{array}$ & Valid \\
\hline
\end{tabular}

Tabel 4.Hasil Black Box Testing Form tambah Data Kategori

\begin{tabular}{|c|c|c|c|c|c|}
\hline No & $\begin{array}{l}\text { Skenario } \\
\text { Pengujian }\end{array}$ & Test Case & $\begin{array}{l}\text { Hasil yang } \\
\text { diharapkan }\end{array}$ & $\begin{array}{c}\text { Hasil } \\
\text { Pengujian }\end{array}$ & Kesimpulan \\
\hline 1 & $\begin{array}{l}\text { Mengosongkan } \\
\text { isian data form } \\
\text { Tambah data } \\
\text { Kategori. Klik } \\
\text { simpan }\end{array}$ & $\begin{array}{c}\text { Kode } \\
\text { Kategori } \\
\text { (kosong) } \\
\text { Nama } \\
\text { Kategori } \\
\text { (kosong) }\end{array}$ & $\begin{array}{l}\text { sistem akan } \\
\text { tidak } \\
\text { memproses }\end{array}$ & $\begin{array}{c}\text { Sesuai } \\
\text { harapan }\end{array}$ & Valid \\
\hline 2 & $\begin{array}{l}\text { mengisi form } \\
\text { kategori dengan } \\
\text { isi data sama }\end{array}$ & $\begin{array}{l}\text { Kode } \\
\text { Kategori } \\
(11)\end{array}$ & $\begin{array}{l}\text { sistem tidak } \\
\text { memproses dan } \\
\text { menampilkan }\end{array}$ & $\begin{array}{c}\text { Sesuai } \\
\text { harapan }\end{array}$ & Valid \\
\hline
\end{tabular}




\begin{tabular}{|l|l|l|l|l|l|}
\cline { 2 - 5 } & $\begin{array}{l}\text { dengan data yang } \\
\text { sudah ada } \\
\text { kemudian, klik } \\
\text { simpan }\end{array}$ & $\begin{array}{c}\text { Nama } \\
\text { Kategori } \\
\text { (kosong) }\end{array}$ & $\begin{array}{l}\text { pesan "Kode } \\
\text { kategori obat } \\
\text { sudah diinput } \\
\text { sebelumnya)" }\end{array}$ & Sesuai \\
harapan & Valid \\
\cline { 2 - 5 } & $\begin{array}{l}\text { mengisi semua } \\
\text { diform kategori } \\
\text { dengan benar } \\
\text { kemudian, klik } \\
\text { simpan }\end{array}$ & $\begin{array}{c}\text { Kode } \\
\text { Kategori } \\
(11) \\
\text { Nama } \\
\text { Kategori } \\
\text { (Obat } \\
\text { Keras) }\end{array}$ & $\begin{array}{l}\text { Sistem akan } \\
\text { menyimpan } \\
\text { data baru yang } \\
\text { diinput. }\end{array}$ & & \\
\hline
\end{tabular}

\section{E. KESIMPULAN}

Dengan selesainya seluruh kegiatan penelitian, analisa sistem, perancangan program hingga tahap implementasi, Sistem Informasi penjualan obat pada apotek yang berbasis web dapat mempermudah dalam membantu aktivitas kegiatan transaksi pembelian dan penjualan obat di Apotek Kauman. Sistem penjualan yang berbasis web memberi akses mudah dan cepat bagi karyawan untuk melakukan proses transaksi penjualan kasir. Dengan pemakaian sistem yang telah terkomputerisasi dan berbasis web dapat mengurangi kesalahan-kesalahan yang terjadi dalam pengimputan produk. Dengan Sistem Informasi penjualan apotek yang berbasis web membantu karyawan/admin dalam control stok obat dan persediaan obat.Penyimpanan data transaksi atau stok obat lebih aman karena berada dalam 1 database yang terintegras.

\section{REFERENSI}

Astuti, P. D. (2013). APerancangan Sistem Informasi Penjualan Obat Pada Apotek Jati Farma Arjosari. ljns.Org, 2.

Fathansyah. (2007). Basis Data.

Hidayat, R., Marlina, S., \& Utami, L. D. (2017). Perancangan Sistem Informasi Penjualan Barang Handmade Berbasis Website Dengan Metode Waterfall. 175-183.

Kusuma, A. Y. (2012). Dengan PHP Membuat Website 30 Juta: Jasakom.

Madcoms. (2011). Kupas Tuntas Adobe Dreamweaver CS5 dengan pemrograman PHP \& MySQL.

Maulidah, N., Pebrianto, R., Supriyadi, R., \& Fauzi, A. (2019). RANCANG BANGUN SISTEM INFORMASI PENERIMAAN SISWA BARU DALAM MENINGKATKAN MUTU LEMBAGA PENDIDIKAN. Speed.

Mujiati, H. (2015). Analisa dan Perancangan Sistem Informasi Stok Obat Pada Apotek Arjowinangun. Jurnal Bianglala Informatika, 3.

Rosa, A. dan S. M. (2011). Modul Pembelajaran Rekayasa Perangkat Lunak Terstruktur dan Berorientasi Objek.

Sibero, A. (2013). Web Programming Powe Pack.

Sutabri, T. 2012. A. S. I. Y. A. O. (n.d.). Analisis Sistem Informasi.

Sutopo, A. H. (2012). Teknologi Informasi dan Komunikasi dalam Pendidikan.

Utami Tri, B. E. P. (2015). Pembangunan Sistem Informasi Penjualan Obat Pada Apotek Punung. - Indonesian on Networking and Security, 4.

Permenkes RI No. 1332/Menkes/SK/X/2002 tanggal 29 Oktober. 